\title{
Institutional Review Board and Research Ethics
}

\author{
Jongbin Kim, Jongsoo Kim
}

Department of Pediatric Dentistry, School of Dentistry, Dankook University

\section{Abstract}

Research ethics is the basic attitude for researchers. Thanks to our predecessors we are able to conduct systematic studies. The current trend of results and the amount of study-oriented assessments make the side effect that researchers conduct SCI (Science Citation Index) studies.

Since the Declaration of Helsinki, the importance of the right, safety and welfare for human participants have improved.

In the present study, I looked into other countries' standpoints concerning the subject of the responsibilities for research ethics and compared them with Korean's standpoint.

Recently, the Ministry of Health and Welfare revised the laws for bioethics and safety. In the point of bioethics, I checked out the function, exemption and process of the Institutional Review Board for the future researcher.

It is suggested to use the research note to verify a study procedure and protect oneself from research misconducts.

Key words : Declaration of Helsinki, Institutional review board, Research ethic, Research note

\section{I. 서 론}

연구윤리란 “연구자가 연구를 수행하면서 지켜야 할 원칙이 나 행동 양식” 을 말한다. 연구윤리는 학문을 탐구하는 연구자의 기본 소양이라 할 수 있다. 아무리 훌륭한 연구 결과 일지라도 그 계획, 진행 과정에서 윤리적 문제를 가진다면 그 결과물은 인정받을 수 없다 ${ }^{1} .1964$ 년 헬싱키 선언을 계기로 의료계에서 는 인간을 대상으로 하는 의학연구의 윤리 원칙을 세우게 되었 달. 많은 국가들에서 연구자가 중심이 되어 연구 윤리 원칙을 세우기 위해 노력하였고 각 정부는 이들의 노력을 뒷받침하는 조치를 취하였다. 하지만 국내의 경우 많은 선학들의 노력에도 몇몇 옳지 못한 사례들로 인해 최근은 정부가 중심이 되어 2013년 2월부터 시행되는 개정「생명윤리 및 안전에 관한 법 률」(이하 “법”이라 한다) 제 10 조에 따라 보건복지부장관이 지
정한 기관생명윤리위원회의 구성 및 운영 등에 관한 사항의 규 정을 의무화 하게 되었다.

이에 따라 국내에서는 IRB (International Review Board) 가 기관생명윤리위원회(이하 기관위원회)라는 용어로 정의되어 그 설립, 구성, 운영 그리고 보고에 이르는 표준절차를 정부가 주도하고 의료기관, 대학, 전문대학, 국책 및 민간연구기관, 식 품 - 화장품 등 기업부설연구소 등 최소 2 천여 개 기관이 의무 설치 대상에 포함될 것으로 예상된다. 더욱이 2013년도 하반기 부터는 설치 · 등록을 하지 않는 기관에는 과태료를 부과하도록 하고 있다 ${ }^{3)}$.

저자는 연구윤리와 기관위원회에서 강조하는 연구 계획서, 기관위원회의 심의절차 그리고 심의면제 사항 등에 관해 알아 보고자 한다. 


\section{II. 본 론}

제2차 세계대전 중에 독일 과학자들이 저지른 비인간적인 실 험에 대한 재판을 통해 1947년 “뉘른베르크 강령” (Nuremberg Code)을 만들게 되었고, 1964년 제18회 세계의 사협회 총회에서 "인간을 대상으로 한 의학 연구에 대한 윤리적 원칙” 인 “헬싱키 선언" (Declaration of Helsinki)이 현재까지 7차에 거친 개정을 하며 이어지고 있다2).

영국은 지역기반 국가주도형으로 RECs (Recearch Ethics Committees, 연구윤리위원회) 가 영국 전역에 87 개가 있으 며, 미국은 민간 중심 국가감시형으로 연방규정 $45 \mathrm{CFR} 46)$ 에 의해 복지부의 재정 지원을 받는 인간대상연구의 IRB 심의를 의무화 하고 있다 ${ }^{3}$.

국내의 경우, 2013년 2월부터 시행되는 개정「생명윤리 및 안전에 관한 법률」 제 12 조 및 법 시행규칙 제 10 조에 따라 보건 복지부장관이 지정한 공용기관생명윤리위원회의 구성 및 운영 등에 관한 사항을 규정을 의무화 하였다.

이러한 노력들은 그동안 관행적으로 해오던 연구 활동을 표 준화하는 데에도 상당한 기여를 하였다. 연구자는 먼저 연구계 획서를 작성하여 기관위원회에 제출하고 심의를 거쳐야 한다. 기관위원회는 "연구계획서가 윤리적 - 과학적으로 타당한지, 연 구대상자 등으로부터 적법한 절차에 따라 동의를 받았는지, 연 구대상자 등의 안전에 관해 문제가 없는지 그리고 연구대상자 등의 개인정보 보호 대책이 잘 수립되었는지 등을 심의" 하게 된 다. 이때 심의는 윤리적인 측면에 중점을 두어 심사하게 된단)

연구자에 대한 윤리 교육도 강조된다. 이는 피험자의 권리보 호와 안전을 보장하고 논문의 출판과정에서 종종 일어나는 "날 조, 변조 그리고 표절(Fabrication, Falsification and Plagiarism)과 같은 연구 부정행위"에 대한 사회적인 관심의 증가도 중요한 요인이다.

따라서 연구자는 연구계획서를 작성하는 시점에서부터 철저 한 준비를 하여야한다. 특히 인간을 대상으로 하는 의학 연구에 서는 필연적으로 인권, 개인정보 보호 등과 같은 문제가 발생하 게 되므로, "연구대상자로부터 개인의 자율성을 존중하여 Informed consent"를 반드시 받아야 한다. 연구 설계에서는 "가능한 과학적으로 유의미한 최소한의 연구대상자만 참여시키 는 것이 윤리적"이며, “목적에 필요한 최소한의 개인정보만을 적법하고 정당하게 수집해야한다" (개인정보보호법 3조 1항).

이러한 절차는 피치 못할 연구 기간과 비용을 증가시킨다. 그 러나 반대로 적법한 절차를 통해 수행된 연구 결과는 예기치 못 한 피검자들로 부터의 소송, 저작권 침해 문제 등으로부터 자유 로워 질 수 있다.

기관위원회의 심의대상은 생명윤리법이 적용되는 연구 (Research)에 해당하면서 인간(또는 인체유래물)을 대상으로 한다. 여기서 연구란 "일반화할 수 있는 지식을 발전시키거나 그에 기여할 수 있도록 고안된 연구개발 및 시험, 평가를 포함 한 체계적인 조사를 의미”한다(미 연방법 HIPPA, 연방규정 $45 \mathrm{CFR} 46$ ). 하지만 단순한 설문조사(출구조사, 여론조사), 기
업 활동과 관련된 조사(시장 조사, 제품 만족도 조사) 등은 연 구라고 보지 않으며 심의대상이 아니다. 가상의 예를 들어 본다 면, 휴대폰 전자파 수치 실험은 연구대상이 휴대폰이므로 심의 대상이 아니고, 휴대폰 전자파가 미치는 영향 실험을 동물을 상 대로 한 경우도 연구대상이 동물이므로 심의대상이 아니다. 하 지만 휴대폰 전자파가 인체에 미치는 영향 실험을 할 경우 연구 대상이 인간이므로 심의대상이 된다. 휴대폰 전자파 수치에 따 른 소비자 선호도 조사의 경우는 연구대상은 인간이지만 단순 한 기업 활동과 관련된 조사이므로 심의대상이 아니다. 원칙적 으로 해당 기관 내에서 수행되는 모든 연구가 심의대상이지만, 외부 공표를 하지 않는 학사, 석사논문에 대해서는 대학 자율로 기관위원회 심의 여부를 결정하도록 권고하고 있다 ${ }^{5}$.

모든 심의는 반드시 사전 심의가 원칙이다. 심의절차에는 심 의면제, 신속심의, 정기심의 그리고 지속심의가 있다. 기관위원 회 운영안내를 참고한 기관위원회 심의절차는 Table 1 과 같다.6.

미국 연방규정 $45 \mathrm{CFR} 46$ 에서 위험이 미미한 경우를 최소한 의 위험(minimal risk)이라 하고 이는 "연구로 인하여 예상되 는 해악 또는 불편의 가능성 및 정도가 일상생활에서 또는 일상 적인 신체적 - 심리적 검진 또는 검사를 행할 때 통상 나타나는 것보다 크지 않은 경우”라 정의 한다. 위원회 사무국에서 연구 계획서를 검토하여 심의대상이 되면 심의면제 여부를 논의하고 승인되지 못할 경우 위원회로 넘어가 신속심의를 하게 되며, 여 기서 부결되면 정기심의로 넘어간다. 정기 심의라 하더라도 "다 년도 연구, 연구대상자에게 중대이상 반응이 발생 그리고 연구

Table 1. 기관생명윤리위원회 심의절차

\begin{tabular}{|c|c|}
\hline $\begin{array}{l}\text { 연구계획서 검토 } \\
\text { (위원회 사무국) }\end{array}$ & $\begin{array}{l}\text { 심의제외 } \\
\text { 연구에 해당하지 않거나, 인간을 대상으로 } \\
\text { 하지 않는 경우 }\end{array}$ \\
\hline$\downarrow$ 심의대상 & \\
\hline $\begin{array}{l}\text { 심의면제 } \\
\text { (위원회 사무국) }\end{array}$ & $\begin{array}{l}\text { 승인 } \\
\text { 연구대상자 및 공공에 미치는 영향이 미미 } \\
\text { 한 경우 }\end{array}$ \\
\hline$\downarrow$ 불승인 & \\
\hline $\begin{array}{l}\text { 신속심의 } \\
\text { (위원회) }\end{array}$ & $\begin{array}{l}\text { 승인 } \\
\text { 위험도가 매우 낮은 연구 }\end{array}$ \\
\hline$\downarrow$ 부결 & \\
\hline $\begin{array}{l}\text { 정기심의 } \\
\text { (위원회) }\end{array}$ & $\begin{array}{l}\text { 승인, 조건부승인, 보완승인, 결정보류 } \\
\text { (반려), 부결(연구중지) } \\
\text { 연구대상자 모집의 적절성 및 공정성 } \\
\text { 충분한 동의에 근거한 연구참여 여부 } \\
\text { 연구대상자 안전보호 대책 마련 여부 } \\
\text { 유사 연구에 있어 이상반응 발생 여부 } \\
\text { 연구방법의 과학적 타당성 등의 심의 }\end{array}$ \\
\hline$\downarrow$ 승인 & \\
\hline $\begin{array}{l}\text { 지속심의 } \\
\text { (위원회) }\end{array}$ & $\begin{array}{l}\text { 승인, 부결 } \\
\text { 다년도 연구(1년에 최소 } 1 \text { 회) } \\
\text { 연구대상자 중대이상반응 발생 시 } \\
\text { 연구계획서 변경 시 }\end{array}$ \\
\hline
\end{tabular}


계획서 변경” 과 같은 경우는 지속심의를 하게 된다.5)

여기서 인간대상연구의 심의면제를 정의하는 법조항을 인용 하면, 법 제 15 조 2 항에 따라 일반대중에게 공개된 정보를 이용 하는 인간대상연구 또는 개인식별정보를 수집하거나 기록하지 않는 인간대상연구로서 다음 각 호의 어느 하나에 해당하는 연 구에 대하여 심의위원회 심의면제를 확인할 수 있다.

1. 연구대상자 등을 직접 조작하거나 그 환경을 조작하는 연 구 중 다음 각 목에 해당하는 연구. 단, 취약한 환경의 연 구대상자를 포함하면 심의를 면제할 수 없다.

가. 약물투여, 혈액채취 등 침습적 행위가 개입되지 않는 연구

나. 신체적 변화가 초래되지 않는 단순 접촉측정 장비 또는 관찰장비만을 사용하는 연구

다.「식품위생법」시행규칙 제 3 조에 따라 판매 등이 허용 되는 식품을 이용하여 맛 또는 질을 평가하는 연구

라. 「화장품법」제 8 조 제 1 항 및 제 2 항에 따른 안전기준에 적합한 화장품을 이용하여 사용감 또는 만족도 등을 조사하는 연구

2. 대면을 하더라도 연구대상자등이 불특정다수이고「개인정 보보호법」제23조에 따른 민감정보를 수집하거나 기록하 지 않는 연구. 단, 취약한 환경의 연구대상자를 포함하면 심의를 면제할 수 없다.

3. 연구대상자등을 직접 대면하지 않는 연구로서 기존의 자 료나 문서를 이용하는 연구

그리고 법 제 36 조제 2 항에 따라 다음 각 호에 해당하는 인체 유래물연구의 심의위원회 심의면제를 확인할 수 있다.

1. 연구자가 개인정보를 수집 - 기록하지 않은 연구 중 다음 각 목의 연구

가. 인체유래물은행이 수집 · 보관하고 있는 인체유래물과 그로부터 얻은 유전정보(이하 “인체유래물등”이라 한 다)를 제공받아 사용하는 연구로서 인체유래물등을 제 공한 인체유래물은행을 통하지 않으면 개인정보를 확 인할 수 없는 연구

나. 의료기관에서 치료 및 진단을 목적으로 사용하고 남은 인체유래물등을 이용하여 정확도 검사 등 검사실 정도 관리 및 검사법 평가 등을 수행하는 연구

다. 인체유래물을 직접 채취하지 않는 경우로서 일반 대중 이 이용할 수 있도록 인체유래물로부터 분리·가공된 연구재료(병원체, 세포주 등을 포함한다)를 사용하는 연구

라. 연구자가 인체유래물 기증자의 개인식별정보를 알 수 없으며, 연구를 통해 얻어진 결과가 기증자 개인의 유 전적 특징과 관계가 없는 연구. 다만, 배아줄기세포주 를 이용한 연구는 제외한다.

2.「초·중등교육법」제 2 조 및「고등교육법」제 2 조에 따른 학교와 보건복지부장관이 정하는 교육기관에서 통상적인 교육과정의 범위에서 실무와 관련하여 수행하는 연구

3. 공중보건상 긴급한 조치가 필요한 상황에서 국가 또는 지
방자치단체가 직접 수행하거나 위탁한 연구. 다만, 이 경우 연구자 또는 해당 연구를 수행하는 기관의 장은 사후에 보 건복지부장관이 지정하는 공용위원회에 보고하여야 한다.

제 1 항 또는 제 2 항에 따른 심의면제를 확인받고자 하는 연구 자는 [별지 제 12 호 서식〕 및 권고서식 제 3 호 심의면제 자가점 검표를 작성하여 연구계획서 또는 해당 인체유래물에 대한 정 보 등 심의면제를 확인할 수 있는 서류를 사무국에 제출하여야 한다.

심의면제대상 연구임에도 불구하고 연구자가 연구의 수행에 필요하다고 판단하는 경우 심의위원회에 심의를 요청할 수 있 다. 이 경우 심의는 신속심의로 한닿.

개인정보보호법상 “민감정보” 란 “사상 - 신념, 노동조합 · 정 당의 가입 - 탈퇴, 정치적 견해, 건강, 성생활 등에 관한 정보와 유전자검사 등의 결과로 얻어진 유전정보, 범죄경력자료에 해 당하는 정보"를 말한다. 미국 연방규정 $45 \mathrm{CFR} 46$ 에서 심의면 제 대상은 "지식의 일반화를 도모하지 않는 연구, 신원확인이 가능한 사적정보를 담고 있지 않는 연구, 기존에 수집된 자료를 이용하는 연구, 공공서비스 평가를 위한 연구 그리고 안전성이 관할청에서 승인된 식품을 이용하는 연구" 등에 대해서는 피험 자 보호를 위한 심위 규정 준수를 요구하지 않는다.

국제의학기구협회(CIOMS) 가이드라인에서는 원칙적으로 모든 의학연구에 대해 윤리심사를 권고하지만 "환자가 긴급한 치료를 필요로 하고, 임상시험용 치료법의 잠재적 유효성에 대 한 증거가 있고, 효과가 월등하다고 알려진 다른 치료법이 없는 경우”를 모두 충족하면 승인이나 허가 전에 의학연구를 수행할 수 있도록 한다. 그러나 이러한 경우라 하더라도 의사는 일주일 이내에 반드시 해당 사례를 세부사항과 취해진 처치 등을 윤리 심사위원회에 보고하도록 하고 있다. 스웨덴의 경우는 대면조 사나 개인정보를 이용한 연구에 대해 승인을 면제하는 경우가 없다 ${ }^{5)}$

기관위원회에서는 "해당 연구가 법령에서 규정한 심의면제 대상에 해당하는 지 여부를 판단하며, 심의면제 대상 연구 항목 을 추가할 수는 없다." 또한 “취약한 환경에 있는 피험자 대상 연구는 기관위원회에서 심의를 면제할 수 없다." 약사법 시행규 칙 별표 3 의 2,2 조 '더' 목에는 취약한 환경에 있는 피험자 (Vulnerable Subject)란 "임상시험 참여와 관련한 이익에 대 한 기대 또는 참여를 거부하는 경우 조직 위계상 상급자로부터 받게 될 불이익에 대한 우려가 자발적인 참여 결정에 영향을 줄 가능성이 있는 피험자(의과대학 - 한의과대학 - 치과대학 · 약학 대학 - 간호대학 학생, 의료기관 - 연구소의 근무자, 제약회사의 직원, 군인 등을 말한다), 불치병에 걸린 사람, 제 31 조의 2 에 따 른 집단시설에 수용되어 있는 사람, 실업자, 빈곤자, 응급상황 에 처한 환자, 소수 인종, 부랑인, 노숙자, 난민, 미성년자 및 자 유의지에 따른 동의를 할 수 없는 피험자"를 말한다 ${ }^{5}$.

생명윤리 및 안전에 관한 법률 제 3 조는 기본 원칙을 정의하 고 있다. 곧 "인간으로서의 존엄과 가치, 인권, 복지, 연구대상 자의 자율성과 사생활 보호 그리고 안전” 을 최우선으로 고려해 야 한다는 것이다. 
실제 연구자가 행하는 대부분의 인간대상연구는 철저히 윤리 적인 관점에서 판단되어야 하며, 아무리 연구 결과로부터 얻을 수 있는 유익함이 크다 하더라도 연구 과정이나 연구대상에 대한 윤리적 기준이 충족되지 못한다면 그 연구는 중단되어야 한다.

기관위원회 즉, 기관생명윤리위원회라고 정의된 IRB는 자발 적인 반성에서 출발하였다. "피험자의 권리를 보장하고, 안전을 확보하며 복지를 유지하려는 노력의 결실” 이라는 다수 학자들 의 의견을 다시 한 번 되새기게 된다.

이렇게 기관위원회에서 심의가 끝난 경우, 연구를 수행하는 과정에서도 연구 윤리는 중요한 요소가 된다. 좋은 연구수행 (Good Research Practice, GRP), 책임 있는 연구수행 (Responsible Conduct of Research, RCR), 연구부정행위 (Research Misconducts) 그리고 의심스런 연구수행 (Questionable Research Pracrtice, QRP) 등의 용어는 연구 활동 중에 겪게 되는 상황에 대한 정의이다. 이들 중에서 우리 가 지양해야할 연구활동은 연구부정행위와 의심스런 연구수행 이다. 연구부정행위는 위조(Fabrication), 변조(Falsification) 그리고 표절(Plagiarism)로 흔히 $\mathrm{FFP}$ 라고 강조되고 있는 것 들이며, 연구자의 책임성과 깊은 연관이 있닥. 미국 연구진실 성국(Office of Research Integrity, QRI)에서 정의하고 있는 연구부정행위에서 먼저 위조란 "실제로 있지 않은 자료 또는 연 구결과 등을 허위로 만들어 내는 행위”를 말하며, 연구자가 의 도적으로 판단을 조작하기 위한 목적이라고 할 수 있다. 이에 반해 변조란 "연구 과정 중의 일부 또는 자료의 일부를 의도적 으로 수정해서 결과를 왜곡하는 행위”를 말하며, “통계학적 검 증 없이 자신이 의도한 결과와 일치하지 않는 자료의 일부를 생 략, 삭제 또는 은폐하는 것” 이라 할 수 있다. 또한 표절은 “타인 의 아이디어, 연구내용 · 결과 등을 정당한 승인 또는 인용 없이 가져다 쓰는 행위"이다.

이에 반해 의심스런 연구행위 또는 연구부적절행위는 "부정 행위처럼 심각한 행위는 아니지만 그렇다고 해서 바람직하거나 좋은 연구수행도 아닌, 결과적으로 책임 있는 연구수행을 방해 하거나 위해하는 행위"를 말한다8). 예를 들어 “논문의 중복게 재, 부당한 논문저자표시 또는 무임승차" 등이 연구부적절행위 에 해당할 수 있으며 연구자들 사이에서 관행으로 행해져 오던 일들이지만 결코 옳은 일이라 할 수 없으니 개선되어야 하겠다.

반면 좋은 연구수행이나 책임 있는 연구수행은 연구의 진실 성이나 객관성을 확보하기 위해 지향해야하는 연구라 할 수 있 겠다. 권9의 연구에 의하면 국가마다 연구부정행위의 정의가 다 른 이유가 그 나라의 진실성 검증 체계와 연관되어 있기 때문이 라고 하였다. 미국은 책임 있는 연구수행을 강조하는데, 이는 명확한 책임성을 구분할 필요성이 있으므로 그 의도성 여부를 가리는 것이 핵심이 되어서 다른 연구자들의 연구활동에 피해 를 주지 않는 책임 있는 연구활동을 강조한다. 아울러 미국은 검증시스템이 체계적이며, 정부나 법원이 개입하는 경우도 있 다. 반면 유럽은 좋은 연구수행을 강조하여, 정직하고 합리적이 며 그리고 자율적인 연구풍토 조성을 이상향으로 여기며 아울 러 바람직한 연구활동의 실천을 강조하여 미국에 비해 연구부
정행위의 범위를 넓고 포괄적으로 정의한다. 그에 반해 검증체 계는 느슨한 것이 특징이다9).

세계 각국의 연구부정행위 유형을 살펴보면 "연구진실성 저 해, 출판부정행위, 데이터의 부적절한 처리 - 보관, 연구저장 부 정행위, 연구관리 부정행위 그리고 개인적 부정행위” 가 있을 수 있다. 이중 위조, 변조 그리고 표절과 같은 연구진실성을 저해 하는 행위에 관해서는 미국, 일본, 유럽 그리고 한국 모두 부정 한 행위로 간주하지만 그 외의 대부분의 유형에 관해서는 유럽 에서만 부정행위로 간주하고 미국, 일본 그리고 한국 등은 연구 부적절행위로 간주하는 추세이다. 다만 한국의 경우 부당한 논 문저자 표시와 같은 출판부정행위나, 제보자에게 위해를 가하 거나 조사를 방해하는 개인적 부정행위의 유형에 관해서는 미 국에 비해 광범위하게 연구부정행위로 인정하고 있다 ${ }^{8)}$.

연구윤리 확보를 위한 연구부정행위 검증과 절차는 교육부 훈령 “연구윤리 확보를 위한 지침”과 미래창조과학부령 “국가 연구개발사업의 관리 등에 관한 규칙" 에서 규정되어 있다. 검증 기관은 제보를 접수한 날로부터 30 일 이내(연구윤리 지침 제 16 조, 예비조사)에 예비조사를 착수하고 6 개월 이내에 본조사 여 부의 결정, 본조사, 의견청취 그리고 판정 등의 과정을 진행하 며 30 일 이내에 이의신청을 받는 과정을 진행하게 된다.

전문기관 및 연구기관 등의 장은 예비조사 및 본조사를 실시 한 경우 조사 종료 후 각각 10 일 이내에 교육부 장관에게 그 결 과를 제출해야 한다.

이상에서 살펴본 것처럼 연구자는 진실성 및 객관성을 확보 하기 위해 연구의 계획, 진행, 결과 발표 그리고 출판에 이르는 전반의 과정에서 많은 노력을 기울여야 한다. 이를 위한 훌륭한 대안 중 하나가 연구노트의 활용이라 할 수 있다. 연구노트는 연구자가 매일의 연구 과정이나 아이디어를 순차적으로 객관인 기록으로 남기는 것이며, 그 과정을 제 3자를 통해 검증받아 두 는 것으로 향후, 자신이 행한 연구의 객관성과 진실성을 담보해 주는 중요한 수단이 된다. 최근에는 전자문서 형식의 연구노트 도 소개되어 그 활용과 자료의 보존이 한층 더 원활해졌다 ${ }^{10)}$. 그 러나 어떠한 규정이나 검증 또는 징계보다도 연구자 자신의 자 율적인 윤리의식의 고양이 무엇보다 중요하다. 연구윤리의 검 증절차나 검증 후속조치 등에 대한 구체적인 정보는 보다 자세 히 공부할 필요가 있으리라 사료된다. 물론 이러한 행정적인 절 차에 대한 공부보다 선행되어야 할 일은 연구부정행위 사전예 방을 위한 교육일 것이며, 또한 지속적인 관리와 교육을 통해 일관성을 유지하기 위한 노력도 동반되어야 하겠다.

\section{III. 결 론}

연구자들은 과거에 비해 어려운 환경에 처해 있다고 생각될 수도 있다. 까다로워진 연구계획서 수립, 기관위원회의 심의절 차 그리고 출판과정에서 위조, 변조 그리고 표절과 같은 연구부 정행위에 대한 검증 등으로 인해 연구 준비 기간에서부터 출판 까지 세심한 주의를 기울여야 한다. 이러한 상황은 연구 기간과 비용을 증가시킬 수 있고 자칫 연구자의 연구 의욕을 꺾는 부작 
용을 낳을 수도 있다. 최근 많은 대학들이 연구 업적 평가에서 상대적으로 SCI (Science Citation Index) 급의 논문을 우대 하는 현실을 고려해볼 때 연구자로 하여금 국내 학술지보다는 국외 학술지를 선호하거나 극단적으로 연구 자체를 포기하는 현상이 더욱 심화될 수밖에 없다고 하겠다.

하지만 연구과정의 표준화, 합리화라는 측면을 고려해서 연 구노트와 같은 수단을 적극 활용한다면 오히려 예기치 않은 연 구대상자로부터의 소송, 특허권의 침해나 저작권 문제 등으로 부터 자신의 권리를 주장할 수 있는 객관적 근거를 마련하는 계 기가 될 수 있으므로, 장기적으로는 불필요한 연구비 지출을 줄 이고 연구업적의 객관성을 확보할 수 있는 계기가 되리라 사료 된다.

\section{References}

1. Assessments on Research Ethics. Available from URL: http://www.cre.or.kr/contents/bioethicsabout/ (Assessed on March 30, (Assessed on March 30, 2014).

2. Assessments on Declaration of Helsinki. Available from URL: http://synapse.koreamed.org/Synapse/ Data/PDFData/0119JKMA/jkma-53-739.pdf (Assessed on March 30, 2014).

3. 2012 IRB academy : $1^{\text {st }}$ publishing standard course workshop of IRB. Ministry of Health and Welfare, 2012.
4. Assessments on 2014 Practical Manual of Institutional Review Board reported by the National Research Foundation of Korea. Available from URL: http://www.cre.or.kr/board/?board = textbook\&no= 1384244 (Assessed on March 30, 2014).

5. 2013 Standard operating procedure for the relevant agency with the law National Bioethics Committee. Ministry of Health and Welfare and Korea Centers for Disease Control and Prevention, 25-49, 2013.

6. 2013 Standard Operating Procedure for Institutional Review Board. Ministry of Health and Welfare, 2426, 2013.

7. 2007 Commentary of Standard Operating Procedure for Guaranty of Institutional Review. Ministry of Education, 32, 2007.

8. 2007 Practice Institutional Review. Ministry of Education, 254, 2007.

9. 2007 Korean Chemical Society Symposium for IRB : $1^{\text {st }}$ publishing standard course workshop of IRB. Korean Chemical Society, 2007.

10. Assessments on 2012 Essential Hand book of Research Note reported by the Korean Intellectual Property Office. Available from URL: http:// www.cre.or.kr/board/?board = textbook\&no $=138265$ 3 (Assessed on March 30, 2014). 


\title{
국문초록
}

\section{기관생명윤리위원회(IRB)와 연구윤리}

\author{
김종빈 · 김종수
}

단국대학교 치과대학 소아치과학교실

연구윤리는 학문을 탐구하는 사람이 갖추어야 할 가장 근본적인 자세라고 할 수 있다. 많은 선학들의 훌륭한 연구 업적 덕 분에 지금의 학문 체계가 마련될 수 있었다. 최근 증가되고 있는 결과 중심의 연구 풍토와 업적을 중시하는 평가 시스템은 일 부 학자로서의 양심을 벗어난 연구를 부추기는 부작용을 낳을 수 있다고 사료된다.

이에 저자는 뉘른베르크 강령과 헬싱키 선언으로 시작된 연구윤리의 개념을 되짚어보고, 이를 강조하는 주체에 대한 각국 의 입장과 국내 실정을 소개하며, 최근 개정된 「생명윤리 및 안전에 관한 법률」에 따른 기관생명윤리위원회의 역할, 심의면 제 그리고 심의절차 등에 관해 검토해보고, 향후 연구자가 숙지해야할 내용을 점검해 보았다. 또한 연구 객관성의 확보와 연 구부정행위에 대한 검증 및 대비를 위해 연구노트의 적극적인 활용을 고려해 보는 것을 제안하는 바이다.

주요어: 기관생명윤리위원회, 연구윤리, 헬싱키 선언, 연구노트 